\title{
Pengaruh Kepemimpinan Transformasional Terhadap Motivasi Kerja Di PT. Mahameru Mekar Djaya
}

\section{Jesslyn Kartawidjaja}

Fakultas Ekonomi, Magister Manajemen Universitas Katolik Parahyangan Bandung Email: jesslyn.kartawidjaja@gmail.com

\begin{abstract}
Employee work motivation is an influential condition to arouse, direct, and maintain individual and group behavior related to the work environment. To increase work motivation, the role of a leader is needed. One of the leadership styles that is believed to increase employee motivation is transformational leadership. Transformational leadership is a leadership style in which the leader creates a vision and an environment that motivates employees to excel by exceeding expectations. This research uses a descriptive method. The quantitative data analysis technique used is descriptive statistical analysis and simple linear regression analysis. This study used a survey census, where the entire population became respondents in this study, as many as 40 people from the Operational Division employees of PT. Mahameru Mekar Djaya Bandung. The results of the data analysis show that transformational leadership is applied by the Operational Manager of PT. Mahameru Mekar Bandung is included in the very strong category and the Operations Department employees have high employee motivation. The results of a simple regression analysis indicate that transformational leadership has a positive and significant effect on work motivation, namely $30.8 \%$.
\end{abstract}

Keywords: leadership; transformational leadership; work motivation

\section{Abstrak}

Motivasi kerja karyawan adalah kondisi yang berpengaruh dalam upaya untuk membangkitkan, mengarahkan, dan memelihara perilaku individu maupun kelompok yang berhubungan dengan lingkungan kerja. Untuk meningkatkan motivasi kerja, peran pemimpin sangat diperlukan. Salah satu gaya kepemimpinan yang diyakini dapat meningkatkan motivasi kerja karyawan adalah kepemimpinan transformasional. Kepemimpinan transformasional adalah gaya kepemimpinan di mana pemimpin menciptakan visi dan lingkungan yang memotivasi para karyawan untuk berprestasi dengan melampaui harapan. Penelitian ini menggunakan metode deskriptif. Teknik analisis data kuantitatif yang digunakan adalah analisis statistik deskriptif dan analisis regresi linear sederhana. Penelitian ini menggunakan sensus survei yakni seluruh populasi menjadi responden dalam penelitian ini yaitu sebanyak 40 orang dari karyawan Bagian Operasional PT. Mahameru Mekar Djaya Bandung. Hasil analisis data menunjukkan bahwa kepemimpinan transformasional yang diterapkan oleh Manajer Operasional PT. Mahameru Mekar Bandung termasuk dalam kategori yang sangat kuat dan karyawan Bagian Operasional memiliki motivasi kerja karyawan yang tinggi. Hasil analisis regresi sederhana 
menunjukkan bahwa kepemimpinan transformasional berpengaruh secara positif dan signifikan terhadap motivasi kerja yaitu sebesar 30,8\%.

Kata kunci: kepemimpinan; kepemimpinan transformasional; motivasi kerja

\section{Pendahuluan}

Di dalam sebuah organisasi, motivasi kerja merupakan salah satu unsur yang sangat penting karena dapat memberikan energi yang mampu menggerakkan segala potensi yang ada, menciptakan keinginan yang tinggi dan luhur, mendukung perilaku manusia agar mau bekerja dengan giat, meningkatkan gairah kebersamaan serta antusias untuk mencapai hasil yang optimal. David McClelland menyebutkan bahwa setiap orang digerakkan oleh tiga kebutuhan dasar yang memengaruhi motivasi, yaitu kebutuhan berprestasi, kebutuhan berkuasa, dan kebutuhan berafiliasi (Mangkunegara, 2016). Kebutuhan untuk berprestasi merupakan refleksi dari dorongan akan upayaupaya serta hasil yang lebih, mencapai standar-standar, dan berusaha keras untuk berhasil. Kebutuhan akan kekuasaan adalah dorongan untuk mencapai otoritas/ kekuasaan untuk memiliki pengaruh terhadap orang lain, sedangkan kebutuhan akan afiliasi adalah keinginan untuk menjalin suatu hubungan antar-personal yang ramah dan akrab (Mangkunegara, 2016).

Motivasi kerja yang tinggi dapat dicapai jika pemimpin mampu menggerakkan, memengaruhi, mengarahkan dan mendorong karyawannya untuk mencapai tujuan tertentu. Dengan demikian, gaya kepemimpinan memiliki peran yang sangat penting dalam memengaruhi dan meningkatkan motivasi kerja karyawan untuk mencapai tujuan organisasi yang telah ditetapkan (Gopal \& Chowdhury, 2014). Kepemimpinan adalah norma atau cara yang digunakan oleh seseorang untuk memengaruhi orang lain yang dilihatnya (Thoha, 2013), (Pujiastuti, 2017). Dalam hal ini pemimpin harus memiliki kemampuan dan kesiapan yang dimiliki untuk dapat memengaruhi, mendorong, mengajak, menuntun, dan mengarahkan agar bawahan atau kelompok menerima pengaruh tersebut dan selanjutnya berbuat sesuatu yang dapat membantu tercapainya suatu tujuan tertentu yang telah ditetapkan (Kamaludin, 2016).

Kepemimpinan tranformasional merupakan model kepemimpinan di mana seorang pemimpin cenderung untuk memberikan motivasi kepada bawahan untuk bekerja lebih baik serta menitikberatkan kepada perilaku untuk membantu transformasi para bawahan agar lebih memiliki motivasi untuk mencapai tujuan organisasi. Dengan demikian, kepemimpinan transformasional akan menciptakan kerjasama dan hubungan yang harmonis antara pimpinan dan bawahan sehingga akan memengaruhi peningkatan motivasi kerja karyawan (Fatmala Sari, 2013). Kepemimpinan transformasional merupakan gaya kepemimpinan yang diyakini paling efektif dalam meningkatkan motivasi kerja karyawan karena dapat membuat pengikutnya terinspirasi, tertantang, dan termotivasi untuk mengejar visi (Natulius, 2011). Kepemimpinan transformasional memiliki beberapa unsur perilaku yaitu pengaruh idealis, motivasi inspirasional, stimulasi intelektual, dan konsiderasi individual. 
Bass mengemukakan bahwa pengaruh idealis, artinya menyediakan visi dan sense of mission, menghasilkan kebanggaan, dan memperoleh rasa hormat serta kepercayaan. Motivasi inspirasional artinya mengkomunikasikan harapan yang tinggi, menggunakan simbol untuk memfokuskan usaha, mengekspresikan tujuan-tujuan penting dalam cara-cara yang sederhana. Stimulasi intelektual yakni proses pemimpin dalam meningkatkan kesadaran para pengikut terhadap masalah-masalah dari perspektif yang baru. Sedangkan konsiderasi individual adalah memberikan perhatian personal, memperlakukan setiap karyawan secara individual, melatih dan memberi saran (Uçar, Eren, \& Erzengin, 2012).

PT. Mahameru Mekar Djaya merupakan perusahaan yang bergerak dalam bidang distribusi barang kebutuhan sehari-hari. Berdasarkan hasil studi pendahuluan yang telah dilakukan, diyakini bahwa terdapat motivasi kerja karyawan yang rendah, khususnya pada karyawan Bagian Operasional PT. Mahameru Mekar Djaya Bandung. Untuk itu di dalam penelitian ini akan diteliti apakah Manajer Operasional PT. Mahameru Mekar Djaya telah melakukan gaya kepemimpinan transformasional, dan seberapa kuat gaya kepemimpinan transformasional yang telah dilakukannya tersebut, bagaimana tingkat motivasi kerja karyawan Bagian Operasional PT. Mahameru Mekar Djaya Bandung, serta bagaimana pengaruh dari kepemimpinan transformasional terhadap motivasi kerja karyawan Bagian Operasional PT. Mahameru Mekar Djaya Bandung.

\section{Metode Penelitian}

Penelitian ini menggunakan metode deskriptif. Penelitian ini bertujuan untuk memberikan gambaran atau pemaparan mengenai permasalahan yang diteliti berdasarkan data. Data tersebut kemudian disajikan, dianalisis, dan diinterpretasikan (Sekaran \& Bougie, 2016). Berdasarkan tujuannya, penelitian ini termasuk ke dalam penelitian terapan (applied research), karena hasil dari penelitian ini ditujukan untuk mengungkapkan fenomena yang terjadi dan membantu perusahaan untuk menyelesaikan permasalahan yang sedang dihadapi (Sekaran \& Bougie, 2016). Teknik analisis data kuantitatif yang digunakan adalah analisis statistik deskriptif dan analisis regresi linear sederhana. Teknik pengumpulan data kepada responden adalah dengan menggunakan kuesioner yang diadopsi dan dikembangkan dari Multifactor Leadership Questionnaire $(M L Q)$ (Talim, 2018). Sedangkan untuk mengukur motivasi kerja, digunakan kuesioner dari The Personal Value Questionnaire (Talim, 2018).

Penelitian dilaksanakan di PT. Mahameru Mekar Djaya Bandung yang beralamat di Jalan Soekarno Hatta Nomor 736, Kelurahan Cimincrang, Kecamatan Gedebage, Kotamadya Bandung, Jawa Barat. Penelitian ini menggunakan sensus survei, di mana seluruh anggota populasi akan dijadikan responden penelitian yaitu sejumlah 40 orang karyawan Bagian Operasional PT. Mahameru Mekar Djaya Bandung.

Adapun langkah-langkah yang dilakukan dalam pengolahan data tersebut adalah sebagai berikut: 
a. Uji Validitas dan Uji Reliabilitas

1. Teknik pengujian untuk mengetahui validitas masing-masing indikator dari variabel kepemimpinan transformasional dan motivasi kerja adalah dengan melihat nilai Corrected Item-Total Correlation. Setiap indikator dinyatakan valid apabila memiliki nilai Corrected Item-Total Correlation atau korelasi lebih besar dari 0,3 (Sulistyastuti, 2017).

2. Teknik pengujian untuk mengetahui validitas masing-masing indikator dari variabel kepemimpinan transformasional dan motivasi kerja adalah dengan melihat nilai Cronbach's Alpha. Instrumen dikatakan reliabel jika memiliki nilai Cronbach's Alpha lebih besar dari 0,6 (Talim, 2018).

b. Analisis Statistik Deskriptif

Analisis statistik deskriptif adalah analisis data dengan mendeskripsikan atau menggambarkan data pada setiap variabel penelitian guna melihat gambaran secara umum penilaian responden untuk masing-masing penelitian (Talim, 2018). Penyajian data dalam penelitian ini adalah menggunakan rata-rata data dari jawaban setiap responden untuk dianalisis. Kategori variabel kepemimpinan transformasional dan motivasi kerja adalah sebagai berikut:

Tabel 1 Kategori Variabel Kepemimpinan Transformasional Dan Motivasi Kerja

\begin{tabular}{cccc}
\hline Kategori & $\begin{array}{c}\text { Nilai Rata- } \\
\text { rata }\end{array}$ & $\begin{array}{c}\text { Kepemimpinan } \\
\text { Transformasional }\end{array}$ & Motivasi Kerja \\
\hline 1. & $1,0-2,0$ & Lemah & Rendah \\
\hline 2. & $2,01-3,0$ & Cukup Kuat & Cukup Tinggi \\
\hline 3. & $3,01-4,0$ & Kuat & Tinggi \\
\hline 4. & $4,01-5,0$ & Sangat Kuat & Sangat Tinggi
\end{tabular}

c. Uji Normalitas

Uji normalitas data bertujuan untuk menguji apakah model regresi, variabel terikat dan variabel bebas keduanya mempunyai distribusi normal atau tidak (Nurwisda \& Rosyadi, 2018). Data yang baik dan layak digunakan dalam penelitian adalah yang memiliki distribusi normal. Dalam penelitian ini penulis akan menggunakan cara dengan melihat kurva normal P - plot. Menurut Singgih Santoso terdapat beberapa cara mendeteksi normalitas dengan melihat penyebaran data (titik) pada sumbu diagonal dari grafik yaitu: (Nafidah, 2015)

- Jika data menyebar di sekitar garis diagonal dan mengikuti arah garis diagonal, maka regresi memenuhi asumsi normalitas.

- Jika data menyebar dari garis diagonal dan atau tidak mengikuti arah garis diagonal, maka model regresi tidak memenuhi asumsi normalitas.

d. Uji Linearitas

Uji linearitas bertujuan untuk mengetahui apakah dua variabel memiliki hubungan yang linear secara signifikan atau tidak. Dasar pengambilan keputusan uji linearitas dalam penelitian ini adalah dengan memperhatikan nilai signifikansinya (Sig.) (Raharjo, 2014). 
- Jika nilai Deviation from Linearity Sig. > 0,05, maka ada hubungan yang linear secara signifikan antara variabel independen dengan variabel dependen.

- Jika nilai Deviation from Linearity Sig. < 0,05, maka tidak ada hubungan yang linear secara signifikan antara variabel independen dengan variabel dependen.

e. Uji Heteroskedastisitas

Uji heteroskedastisitas bertujuan untuk menguji terjadinya perbedaan variansi (variance) dari nilai residual pada suatu periode pengamatan ke periode pengamatan yang lainnya (Uviyanti \& Pramuka, 2020). Dalam penelitian ini penulis akan menggunakan cara dengan melihat pola gambar Scatterplots. Adapun pedoman yang digunakan untuk melihat pola gambar Scatterplots adalah sebagai berikut. Tidak terjadi gejala atau masalah heteroskedastisitas apabila: (Raharjo, 2017)

- Titik-titik data penyebar di atas dan di bawah atau di sekitar angka 0.

- Titik-titik tidak mengumpul hanya di atas atau di bawah saja.

- Penyebaran titik-titik data tidak boleh membentuk pola bergelombang melebar kemudian menyempit dan melebar kembali.

- Penyebaran titik-titik data tidak berpola.

f. Analisis Regresi Linear

Analisis regresi linear digunakan untuk mengetahui arah hubungan antara variabel independen dengan variabel dependen, apakah positif atau negatif serta untuk memprediksi nilai dari variabel dependen apabila nilai variabel independen mengalami kenaikan atau penurunan. Persamaan umum regresi linear sederhana (Sugiyono, 2017) adalah:

$$
Y=a+b x
$$

Keterangan:

$Y^{\prime}=$ Subjek/ nilai dalam variabel dependen yang diprediksikan.

$\mathrm{a}=$ Harga $\mathrm{Y}$, bila $\mathrm{X}=0$ (harga konstan)

$\mathrm{b}=$ Angka arah atau koefisien regresi, yang menunjukkan angka peningkatan ataupun penurunan variabel dependen yang didasarkan pada variabel independen. Apabila b (+) maka naik, dan bila b (-), maka terjadi penurunan.

$\mathrm{X}=$ Subjek pada variabel independen yang mempunyai nilai tertentu.

Analisis regresi linear sederhana ini dilakukan dengan bantuan program Statistical Package for the Social Sciences (SPSS).

\section{Hasil dan Pembahasan}

Semua indikator dari variabel kepemimpinan transformasional dan motivasi kerja dinyatakan valid karena semuanya memiliki nilai Corrected Item-Total Correlation lebih besar dari 0,3. Hasil pengukuran variabel kepemimpinan transformasional dan motivasi kerja dinyatakan reliabel karena semuanya memiliki nilai Cronbach's Alpha lebih besar dari 0,6.

Berdasarkan analisis deskriptif variabel kepemimpinan transformasional, didapat hasil bahwa dimensi pengaruh idealis memiliki nilai rata-rata sebesar 4,05 dengan kategori sangat kuat. Artinya, karyawan merasakan sangat kuat bahwa pemimpin 
merupakan model inspirasi bagi mereka untuk menerima nilai-nilai, norma dan prinsipprinsip bersama. Motivasi inspirasional memiliki perolehan nilai rata-rata sebesar 4,34 dengan kategori sangat kuat. Artinya karyawan merasakan sangat kuat perilaku pemimpin yang dapat merangsang antusias dan mengatakan hal-hal yang bersifat membangun kepercayaan diri karyawan terhadap kemampuan dalam menyelesaikan tugas dan mencapai tujuan kelompok. Dimensi stimulasi intelektual memperoleh nilai rata-rata sebesar 3,80 dengan kategori kuat. Artinya, karyawan merasakan kuat sikap pemimpin yang merangsang timbulnya ide dan inovasi serta memberikan solusi kreatif terhadap permasalahan yang dihadapi oleh karyawan, dan dimensi konsiderasi individual memperoleh nilai rata-rata sebesar 4,01 dengan kategori sangat kuat. Artinya, karyawan merasakan sangat kuat sikap pemimpin yang memberikan perhatian, saran, serta memperlakukan karyawan secara individual sesuai dengan kebutuhan dan kemampuan masing-masing individu. Kepemimpinan transformasional memiliki nilai rata-rata total yaitu sebesar 4,02 dengan kategori sangat kuat. Dengan demikian dapat disimpulkan bahwa Manajer Operasional PT. Mahameru Mekar Djaya telah menerapkan gaya kepemimpinan transformasional di dalam perusahaan dan karyawan Bagian Operasional merasakan sangat kuat kepemimpinan yang berfokus kepada proses di mana pemimpin dan karyawan saling meningkatkan moralitas dan motivasi bersama.

Berdasarkan analisis deskriptif variabel motivasi kerja, didapat hasil bahwa dimensi kebutuhan akan pencapaian memiliki nilai rata-rata sebesar 3,93 dengan kategori tinggi. Artinya, secara umum terdapat dorongan yang tinggi dari karyawan untuk berusaha berhasil dan mencapai standar-standar yang telah ditetapkan perusahaan serta memiliki keinginan untuk mencapai prestasi yang tinggi. Dimensi kebutuhan akan kekuasaan memiliki nilai rata-rata sebesar 3,30 dengan kategori tinggi. Dengan demikian diketahui bahwa karyawan memiliki dorongan yang tinggi untuk dapat mengendalikan dan memengaruhi orang lain. Dimensi kebutuhan akan afiliasi memiliki nilai rata-rata sebesar 3,76 dengan kategori tinggi. Nilai ini menunjukkan bahwa terdapat dorongan yang tinggi dari karyawan untuk menjalin suatu hubungan antarpersonal yang erat, ramah dan akrab. Variabel motivasi kerja memiliki nilai rata-rata total yaitu sebesar 3,31 dengan kategori tinggi. Dengan demikian dapat disimpulkan bahwa motivasi kerja karyawan pada Bagian Operasional di PT. Mahameru Mekar Djaya Bandung termasuk ke dalam kategori yang tinggi.

Dari hasil uji p-plot, dapat terlihat titik-titik yang mengikuti dan mendekati garis diagonalnya sehingga dapat disimpulkan bahwa data penelitian ini memiliki penyebaran dan berdistribusi normal. Dengan normalnya data pada penelitian ini, maka penelitian ini dapat dilanjutkan.

Berdasarkan nilai signifikansi (Sig.) pada hasil uji linearitas diperoleh nilai Deviation from Linearity Sig. sebesar 0,059 yang mana nilai tersebut lebih besar dari 0,05. Dengan demikian dapat disimpulkan bahwa terdapat hubungan linear secara signifikan antara variabel independen (kepemimpinan transformasional) dengan variabel dependen (motivasi kerja). 
Dari hasil Scatterplot untuk menguji heteroskedastisitas, menunjukkan penyebaran titik-titik data yang menyebar di atas dan di bawah atau di sekitar angka 0 . Titik-titik data tidak mengumpul hanya di atas atau di bawah saja. Penyebaran titik juga tidak membentuk suatu pola. Dengan demikian dapat disimpulkan bahwa tidak terjadi masalah heteroskedastisitas sehingga model regresi yang baik dan ideal dapat terpenuhi.

Hasil persamaan regresi linear sederhana kepemimpinan transformasional (X) terhadap motivasi kerja (Y) adalah sebagai berikut:

\section{$\mathbf{Y}=\mathbf{4 5 , 0 1 0 + 0 , 5 7 2 X}$}

$\mathrm{a}=$ angka konstan dari unstandardised coefficients, yang nilainya sebesar 45,010. Angka ini merupakan angka konstan yang memiliki arti bahwa jika tidak ada kepemimpinan transformasional (X), maka nilai konsisten dari Motivasi Kerja (Y) adalah sebesar 45,010.

$\mathrm{b}=$ angka koefisien regresi, yang nilainya sebesar 0,572. Angka ini mengandung arti bahwa setiap penambahan $1 \%$ tingkat kepemimpinan transformasional $(\mathrm{X})$, maka motivasi kerja (Y) akan meningkat sebesar 0,572.

Berdasarkan hasil persamaan regresi tersebut di atas, nilai koefisien regresi bernilai (+), dengan demikian dapat dikatakan bahwa kepemimpinan transformasional (X) berpengaruh positif terhadap motivasi kerja (Y). Nilai signifikansi (Sig.) yang didapat yaitu sebesar 0,000 . Nilai ini lebih kecil dibandingkan dengan nilai probabilitas 0,05. Dengan demikian dapat disimpulkan bahwa kepemimpinan transformasional (X) berpengaruh signifikan terhadap motivasi kerja karyawan $(\mathrm{Y})$.

Dapat diketahui pula nilai $R$ Square yaitu sebesar 0,308. Nilai ini mengandung arti bahwa pengaruh kepemimpinan transformasional $(\mathrm{X})$ terhadap motivasi kerja $(\mathrm{Y})$ adalah sebesar $30,8 \%$. Sedangkan sisanya sebesar $69,2 \%$ motivasi kerja dipengaruhi oleh variabel lainnya yang tidak diketahui dan tidak termasuk dalam analisis regresi ini.

Berdasarkan hasil analisis regresi linear sederhana tersebut di atas, maka dapat disimpulkan bahwa kepemimpinan transformasional berpengaruh secara positif dan signifikan terhadap motivasi kerja yaitu sebesar 30,8\% dan sisanya sebesar 69,2\% dipengaruhi oleh variabel lainnya yang tidak diketahui. Hasil penelitian ini selaras dengan penelitian yang dilakukan oleh (Savitri, 2014) bahwa terdapat pengaruh dari gaya kepemimpinan transformasional terhadap motivasi kerja pada perawat di Instalasi Rawat Inap II Rumah Sakit Umum Dr. Saiful Anwar Malang, serta penelitian yang dilakukan (Ninda \& Iskandar, 2015) bahwa secara simultan terdapat pengaruh yang signifikan dan positif dari dimensi pengaruh idealis, motivasi inspirasional, stimulasi intelektual dan konsiderasi individual secara keseluruhan terhadap variabel motivasi kerja.

\section{Kesimpulan}

Berdasarkan hasil penelitian yang dilakukan oleh peneliti, dapat ditarik kesimpulan sebagai berikut:

Manajer Operasional dari PT. Mahameru Mekar Djaya Bandung telah menerapkan gaya kepemimpinan transformasional, dan karyawan Bagian Operasional 
merasakan sangat kuat gaya kepemimpinan transformasional yang telah diterapkan oleh Manajer Operasional tersebut. Pada umumnya karyawan Bagian Operasional PT. Mahameru Mekar Djaya Bandung memiliki motivasi kerja yang tinggi.

Berdasarkan hasil analisis regresi linear sederhana yang telah dilakukan, dapat diketahui bahwa kepemimpinan transformasional berpengaruh secara positif dan signifikan terhadap motivasi kerja yaitu sebesar 30,8\% dan sisanya sebesar 69,2\% dipengaruhi oleh variabel lainnya yang tidak diketahui. Dengan nilai pengaruh yang cukup kecil tersebut, yaitu sebesar 30,8\%, maka perlu dilakukan penelitian lebih lanjut untuk mencari variabel-variabel lainnya yang memiliki pengaruh yang lebih besar terhadap motivasi kerja karyawan dibandingkan dengan kepemimpinan transformasional. 


\section{BIBLIOGRAFI}

Fatmala Sari, Ani Endarti Diana. (2013). Pengaruh Kepemimpinan Transformasional Terhadap Motivasi Kerja Pegawai Di Kantor Kecamatan Simo Kabupaten Boyolali. Universitas Muhammadiyah Surakarta.

Gopal, R., \& Chowdhury, Rima Ghose. (2014). Leadership styles and employee motivation: An empirical investigation in a leading oil company in India. International Journal of Research in Business Management, 2(5), 1-10.

Kamaludin, Kamaludin. (2016). Pengaruh Peran Kepemimpinan Kepala Sekolah Dan Iklim Sekolah Terhadap Kinerja Guru. Syntax Literate; Jurnal Ilmiah Indonesia, 1(3), 17-29.

Mangkunegara, A. A. Anwar Prabu. (2016). Manajemen sumber daya manusia perusahaan. PT. Remaja Rosdakarya.

Nafidah, Nurun. (2015). Pengaruh kinerja pustakawan terhadap kepuasan pemustaka pada perpustakaan Universitas Indonesia.

Natulius, F. (2011). Analisa kepemimpinan transaksional dan transformasional untuk meningkatkan kerja sama tim dan kinerja waktu proyek (Studi Kasus pada Perusahaan PT. X). Jakarta: Universitas Indonesia.

Ninda, Prasdita Intan, \& Iskandar, Dadang. (2015). Pengaruh Kepemimpinan Transormasional Terhadap Motivasi Kerja (Studi Kasus: Karyawan Human Capital Center (HCC) PT Telkom Japati Bandung. EProceedings of Management, 2(3).

Nurwisda, Delaga, \& Rosyadi, Noor. (2018). Pengaruh Kebutuhan Fisiologis, Keamanan, Sosial, Penghargaan Dan Aktualisasi Diri Terhadap Prestasi Kerja Pegawai Puskesmas Petarukan Kab. Pemalang. Syntax Literate; Jurnal Ilmiah Indonesia, 3(10), 30-46.

Pujiastuti, Endang. (2017). Hubungan Antara Kompetensi Profesional Tenaga Medis, Budaya Kerja Dan Gaya Kepemimpinan Dengan Mutu Pelayanan Pasien Rawat Inap Di Rumah Sakit Waled Kab. Cirebon. Syntax Literate; Jurnal Ilmiah Indonesia, 2(4), 34-65.

Raharjo, Sahid. (2014). Cara Melakukan Uji Linearitas dengan Program SPSS. Blog Sahid Raharjo.

Raharjo, Sahid. (2017). Panduan Uji Heteroskedastisitas dengan Gambar Scatterplots SPSS. Retrieved from SPSS Indonesia: www. spssindonesia. com.

Sekaran, Uma, \& Bougie, Roger. (2016). Research methods for business: A skill building approach. John Wiley \& Sons.

Sugiyono. (2017). Metode Penelitian Pendidikan. Bandung: Alfabeta. 
Sulistyastuti, Erwan Agus Purwanto dan Dyah Ratih. (2017). Metode Penelitian Kuantitatif. Yogyakarta: Gava Media.

Talim, M. Banowati. (2018). Analisis hubungan kepemimpinan transformasional dengan motivasi kerja pegawai di lembaga pendidikan tinggi. Program Magister Manajemen Program Pascasarjana Universitas Katolik Parahyangan.

Thoha, Mifiah. (2013). Kepemimpinan Dalam Manajemen, edisi 1, Jakarta, PT. Raja Grafindo.

Uçar, Ahmet Cengiz, Eren, Erol, \& Erzengin, Esra. (2012). Determination of the relationship between leadership perceptions of blue collars and organizational outcomes by using MLQ analysis. Procedia-Social and Behavioral Sciences, 41, 196-208.

Uviyanti, Siti, \& Pramuka, Bambang Agus. (2020). Pengaruh Sistem Informasi Akuntansi Terhadap Kualitas Laporan Bantuan Operasional Sekolah (Bos). Syntax Literate; Jurnal Ilmiah Indonesia, 5(7), 471-480. 